\title{
Validation of a multiparameter model to investigate torrefied biomass pelletization behavior
}

Puig Arnavat, Maria; Ahrenfeldt, Jesper; Henriksen, Ulrik Birk

\section{Published in:}

Energy \& Fuels

Link to article, DOI:

10.1021/acs.energyfuels.6b02895

Publication date:

2017

Document Version

Peer reviewed version

Link back to DTU Orbit

Citation (APA):

Puig Arnavat, M., Ahrenfeldt, J., \& Henriksen, U. B. (2017). Validation of a multiparameter model to investigate torrefied biomass pelletization behavior. Energy \& Fuels, 31(2), 1644-1649.

https://doi.org/10.1021/acs.energyfuels.6b02895

\section{General rights}

Copyright and moral rights for the publications made accessible in the public portal are retained by the authors and/or other copyright owners and it is a condition of accessing publications that users recognise and abide by the legal requirements associated with these rights.

- Users may download and print one copy of any publication from the public portal for the purpose of private study or research.

- You may not further distribute the material or use it for any profit-making activity or commercial gain

- You may freely distribute the URL identifying the publication in the public portal 


\title{
Validation of a multiparameter model to investigate
}

\section{torrefied biomass pelletization behavior}

\author{
Maria Puig-Arnavat*, Jesper Ahrenfeldt, Ulrik B. Henriksen
}

Department of Chemical and Biochemical Engineering, Technical University of Denmark, 2800

Kgs. Lyngby, Denmark

* Corresponding author: mpar@kt.dtu.dk

\begin{abstract}
The present study aims to apply and validate a simple model describing the forces that are built up along the dies of a pellet press matrix to the pelletization of torrefied biomass. The model combines a theoretical background with the use of a single pellet press to describe the pelletizing behavior of torrefied material in an industrial scale pellet mill. Wet torrefaction and dry torrefaction pretreatments are considered in the study. Both torrefaction concepts produce a fuel with enhanced properties including a lower moisture content, higher calorific value, and better friability. The fuel shows closer properties to coal and it is more economical to transport and better to store due to its hydrophobic characteristics. The goal of the present study is to allow for a fast estimation of important pelletization process parameters, to get a better understanding of the pelletization process and to avoid time consuming as well as expensive trial and error experiments.
\end{abstract}

\section{KEYWORDS}

Pelletization, dry torrefaction, wet torrefaction, willow, giant reed, modelling

\section{INTRODUCTION}


Biomass can make an important contribution and help the development of future sustainable and renewable energy systems, due to its potential to completely replace fossil fuels (coal and oil) in many applications. However, the efficient use of biomass and complete replacement of fossil fuels, in systems originally designed for them, is limited due to some undesirable characteristics that biomass presents ${ }^{1}$. Some of these characteristics are high heterogeneity, high moisture content, high alkali content, low heating value, low bulk density, poor grindability as well as storage problems ${ }^{2-5}$. So, in order to improve its properties for industrial applications, biomass often needs to be pretreated. Torrefaction and pelletization are two remarkable pretreatment processes and their combination results in the production of solid fuels with enhanced physical, chemical and fuel properties than the original raw biomass ${ }^{2}$. These energy dense solid fuels are an interesting option as replacement for coal in existing power plants ${ }^{6}$.

Presently, two torrefaction processes exist: wet and dry ${ }^{2,3,7}$. Dry torrefaction (DT) has received a lot of attention in the last twenty years and it is now available in the market. However, the process is not completely optimized and different feedstocks and concepts require different operating conditions that have not been well determined yet ${ }^{8}$. Dry torrefaction is defined as a thermochemical pretreatment process typically at $200-300{ }^{\circ} \mathrm{C}$ in the absence of oxygen, at atmospheric pressure, with low heating rates (less than $50{ }^{\circ} \mathrm{C} / \mathrm{min}$ ) and a holding time at maximum temperature of less than 1 hour.

In contrast to dry torrefaction where biomass is torrefied in the gas phase, wet torrefaction (WT) takes place in hydrothermal media or hot compressed water at temperatures between 180 and $260^{\circ} \mathrm{C}$. WT has also been considered for energy applications (gasification, combustion and pyrolysis $)^{8-10}$ but to a lesser extent than DT and mainly with a focus on using low cost biomass sources. WT is well suited to upgrade feedstocks with undesirable characteristics, such as: high moisture and ash content, fibrous composition, and low bulk density ${ }^{11}$. It modifies the structure 
making the fibers more brittle, while water typically dissolves more than $98 \%$ of the chloride and alkali salts ${ }^{11}$. This treated biomass can be mechanically dewatered, which minimizes the need for thermal drying.

Both torrefaction concepts produce a fuel with improved properties including a higher calorific value, lower equilibrium moisture content and improved friability $y^{2,8,12,13}$. During combustion, the fuel has closer properties to coal, such as more stable burning characteristics, than raw biomass ${ }^{14,15}$. During gasification, the efficiency and the quality of the syngas are improved ${ }^{16,17}$. For fastpyrolysis, the yield of byproducts is decreased and the quality of bio-oil improved by the use of torrefied biomass instead of raw biomass ${ }^{18,19}$. In addition, torrefied biomass pellets have a higher volumetric energy density than those made from untreated biomass. These properties allow pelletized torrefied biomass to be more economical to transport and better to store due to its hydrophobic characteristics ${ }^{20}$.

The increasing demand of pellets for energy purposes together with the advantageous characteristics that pellets from torrefied biomass present, call for further investigation and optimization of the torrefied biomass pelletization process. Different studies can be found concerning pelletization of DT biomass ${ }^{21-27}$ but very few regarding pelletization of WT biomass ${ }^{8,28}$. However, several studies regarding pelletizing of pretreated biomass in a process similar to WT can be found in the literature under the name "hydrothermal carbonization” (HTC) ${ }^{29-32}$. Although sometimes WT has been referred as HTC; the two processes are different. In WT, the energy efficiency is more critical and thus it is usually carried out at lower temperatures. WT focuses on producing high-grade solid fuels for energy applications. On the other hand, HTC is used to produce charcoal that can be used as a fuel but also in other applications as activated carbon, fertilizer, soil enhancer, etc. ${ }^{8}$ These studies show that there are many parameters and variables that affect the biomass pelletization process and the resulting product characteristics. Rudolfsson et al. ${ }^{33}$ presented a study 
that mapped the combined effects of key parameters of torrefaction and pelletization on the pelletizing process and the resulting pellet quality. Nielsen et al. ${ }^{34}$ focused on the study of the pelletization process and divided it into three components (compression, flow and friction) that together represent the overall energy consumption of the process. Tumuluru et al. ${ }^{35}$ reviewed different compression models used in biomass densification. However, optimization of pelletization process is still mainly based on trial and error and personal experience. Thus, finding the optimal processing conditions is time consuming and expensive. In this sense, Holm et al. ${ }^{36,37}$ developed a theoretical model that describes the forces built up along the dies of the pellet mill matrix. The model combines modelling with the use of a single pellet press to imitate the biomass pelletizing behavior in industrial scale pellet mills. This permits a rapid determination of optimal values for important process parameters such as moisture content, pelletization temperature and die length. The model was successfully validated for Scotch pine shavings and European beech shavings ${ }^{38}$ but not for torrefied biomass. Pelletization of torrefied biomass has, for long time, been an underestimated bottleneck in the production process of torrefied fuels and their commercialization ${ }^{39}$. For this reason, further efforts are required to study the pelletization of torrefied materials, especially WT biomass, in large scale pellet mills. In this sense, the present paper applies the mentioned model to the pelletization of DT willow and WT giant reed. It wants to prove the usefulness of the model also for torrefied biomass and to provide the large scale pellet mills with an easy and inexpensive procedure for the evaluation of the pelletization behavior of different torrefied materials.

\section{MATERIALS AND METHODS}

\subsection{Materials}


In the present study, two different kinds of biomass were considered: willow and giant reed (Arundo donax). In both cases, the pre-treatment (dry and wet torrefaction) was carried out in the Energy research Centre of the Netherlands (ECN) as part of the LogistEC project activities.

Giant reed was provided by CRIBE (Centro Interuniversitario di Ricerca sulle Biomesse da Energia, Pisa, Italy) and pretreated using wet torrefaction. The wet torrefaction pretreatment principle, named TORWASH by ECN, is summarized in Figure 1.

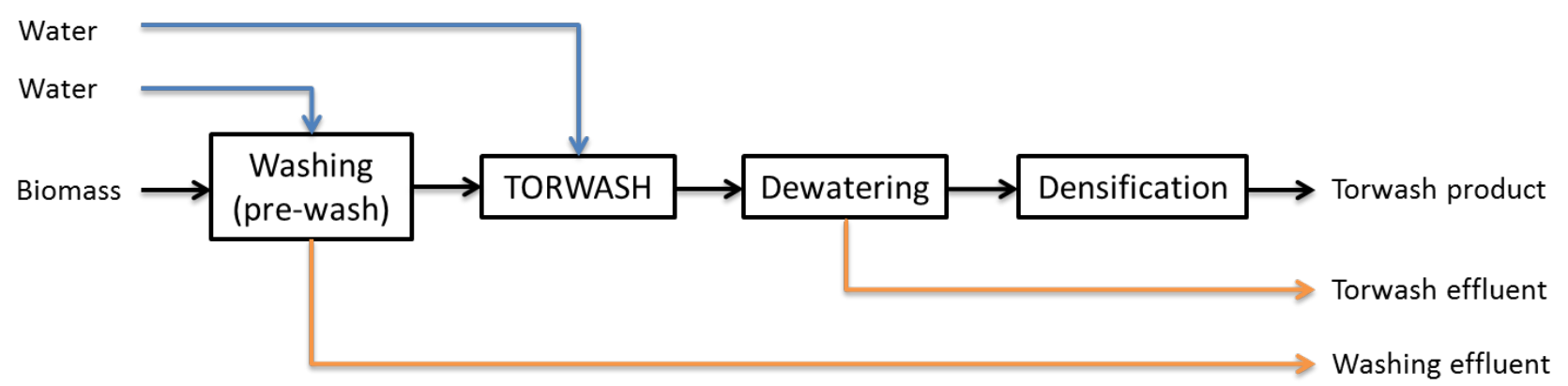

Figure 1. TORWASH (wet torrefaction) process scheme

Giant reed was milled until the particle size was below $1 \mathrm{~cm}$. Then, it was washed, inside a mesh bag, for 15 minutes in warm demineralized water in an industrial washing machine. After this step, the biomass was dried by spinning and $90 \%$ of the dry matter was recovered. Washed giant reed was torwashed in an autoclave for $30 \mathrm{~min}$ at $200^{\circ} \mathrm{C}$. Demineralized water was added at a ratio of $\mathrm{L} / \mathrm{S}$ = 7.5 (dry base). After cooling, the content was filtered. The wet filter cakes were collected and pressed in a Carver Die industrial press at 67 bar static pressure to get wet discs. $60 \%$ of the mass, containing $68 \%$ of the energy originally present in the feedstock, was recovered after the wet torrefaction pretreatment. A more detailed description of the process as well as composition of the effluents can be found elsewhere ${ }^{40}$. 
Willow was provided by SGB (SG Biodrying Ltd, Retford, UK) and torrefied (dry torrefaction) in the pilot scale facilities of ECN. The torrefaction was carried out during 45 minutes at $260^{\circ} \mathrm{C}$.

The moisture content of the samples received from ECN was measured by drying them at $105^{\circ} \mathrm{C}$ for 24h in an oven (according to ISO 18134-1:2015) and it was $1.43 \%$ for DT willow and $9.30 \%$ for WT giant reed. Both samples were ground in a knife mill (Retsch SM 2000) with a $\varnothing 4 \mathrm{~mm}$ screen resulting in the particle distribution presented in Figure 2. The samples were sieved according to the standard EN 15149-2:2010. Only the fraction in the particle size range of $0.25-1 \mathrm{~mm}$ was used for the tests in the single pellet press.

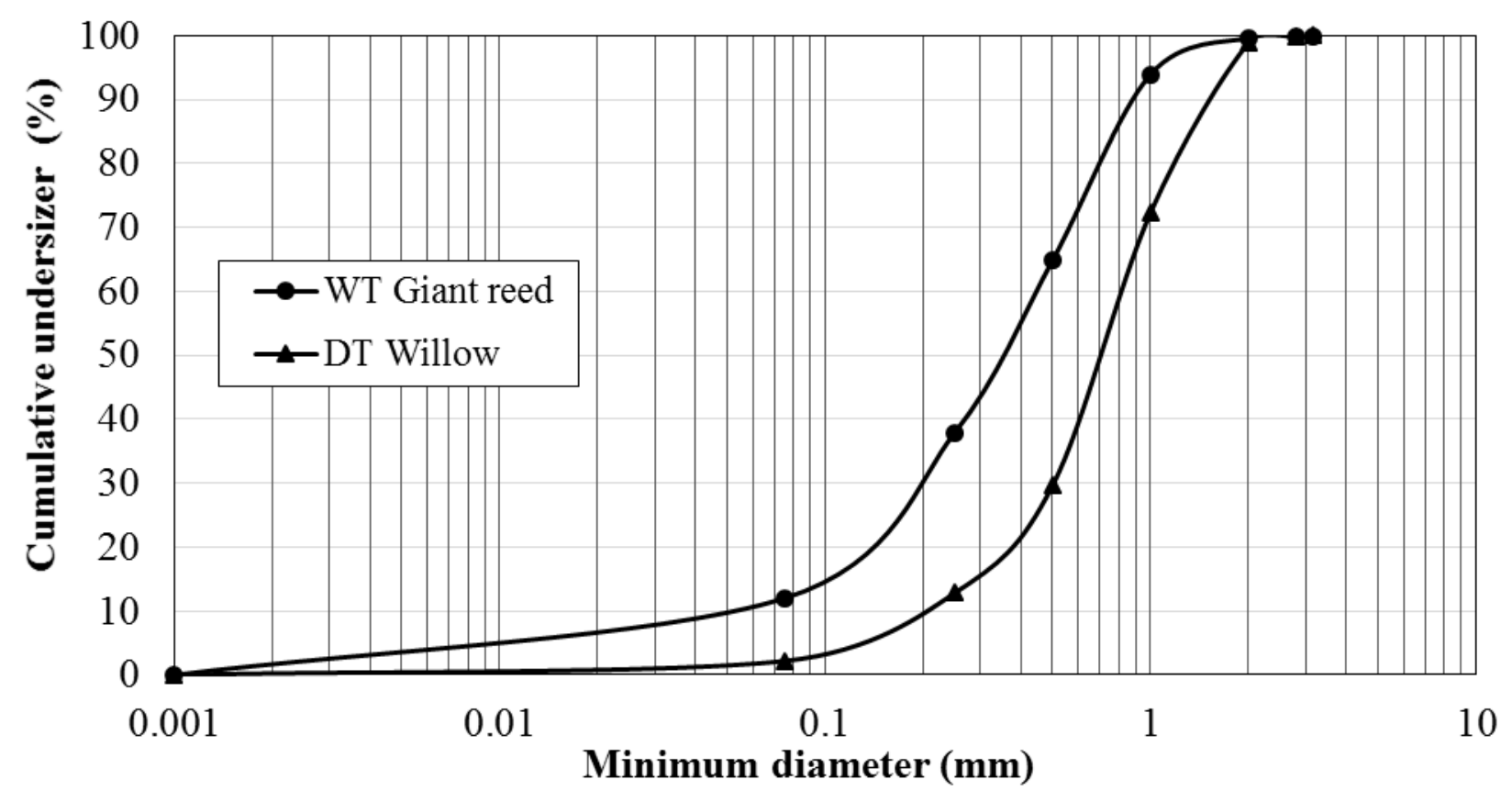

Figure 2. Particle size distribution after grinding in a knife mill, with a $\varnothing 4 \mathrm{~mm}$ sieve, the WT giant reed and DT willow samples.

\subsection{Methods}


Holm et al. ${ }^{36}$ presented a theoretical model, based on the Poisson's effect, that describes the forces built up in a press die when the pellet is pressed through the die. The Poisson's effect, measured by the Poisson ratio $(v)$, is the expansion in directions perpendicular to the direction of compression. Because wood is an orthotropic material, $v$ is different in each direction (x, y and $\mathrm{z}$ ). In the model, wood fibers are assumed to be perpendicularly oriented to the long direction of the die channel. Other terms also included in the model are: the compression ratio $(c)$ and the material specific sliding friction coefficient $(\mu)$. The prestressing term $\left(P_{N 0}\right)$ is a constant term and accounts for the inelasticity. So, the pelletizing pressure $\left(P_{x}\right)$ that is required to press out a pellet of $x$ length can be calculated as follows ${ }^{37}$ :

$P_{x}(x)=\frac{P_{N 0}}{v_{L R}}\left(e^{2 \mu v_{L R} x / r}-1\right)$

Eq. 1

Where $v_{L R}$ is the Poisson's ratio, $P_{N o}$ is the prestressing term, $r$ is the radius, $\mu$ is the sliding friction coefficient and $x$ is the length of the die channel.

The problem that Eq. 1 has is that $P_{\text {No }}$ needs to be determined experimentally and $v$ and $\mu$ values are difficult to find for different materials because they depend on the type of biomass, the moisture content and the temperature. Holm et al. ${ }^{37}$ solved this problem by defining two new parameters ( $U$ and $J$ ) that result from the combination of $\mu, v$ and $P_{N o} . U$ and $J$ parameters can be estimated by conducting few experimental tests in a single pellet press and are defined as follows:

$$
U=\mu P_{N 0}
$$

$J=\mu v_{L R}$

$c=\frac{x}{2 r}$ Eq. 4

Introducing Eq 2-4 in Eq 1 leads to:

$P_{x}(c)=\frac{U}{J}\left(e^{4 J c}-1\right)$ Eq. 5

As it was shown in ${ }^{36}$, for small $c(c<<1)$, Eq. 5 is given as 
$P_{x}(c) \cong 4 U_{c}$

Eq. 6

So, in this limit of small $c$, it is possible to determine $U$ from the slope of the linear fit of $P_{x}$ versus

c. Once $U$ value is known, $J$ value can be determined by fitting Eq. 5 to all the data points measured experimentally in the single pellet press. For this procedure to be valid, the measurements need to be carried out at small compression ratios so the differences in Poisson's ratios can be neglected. The extrapolation to high $c$ values involves introducing a degree of uncertainty. But the model has, in previous works, given a fair estimation of the pelletizing pressure at high $c$ values ${ }^{38}$. The procedure followed in the present study was to make 3 or 4 pelletizing tests in a single pellet press unit in the linear region $(0.7<c)$. Then, $U$ was calculated from the linear slope obtained from the linear fit applied to the experimental data in the linear region (including 0,0). Later, five more experimental measurements were carried out at higher compression ratios $(1<c<4)$ and the $J$ value was determined by adjusting a nonlinear fit of Eq. 5 to all the data points measured experimentally in the single pellet press. In this fit, the previously obtained value of $U$ was used. At least, four repetitions were done for each measurement. The average value was used and the standard deviation calculated. For each biomass, the measurements were carried out at four different die temperatures $\left(60,80,100\right.$ and $\left.120^{\circ} \mathrm{C}\right)$. All the pellets made in these tests were built up in sequential layers to emulate the pellet production process in an industrial pellet mill ${ }^{38}$.

\subsection{Single pellet press}

The single pellet press used to produce the pellets was designed and made at DTU (Technical University of Denmark) ${ }^{41}$. It produces one pellet at the time in a cylindrical $8 \mathrm{~mm}$ diameter hardened steel die. The die is surrounded by heating elements that allow for operation at different temperatures by using a thermocouple connected to a control unit. The single pellet press is thermally insulated and the pressure is applied by a hydraulic press on a tightly fitted piston against 
a fixed backstop (Figure 3). A $50 \mathrm{kN}$ load cell detects the force applied. When the pellet reaches the desired size, the back stop is removed and the pressure applied on the piston is increased until the pellet starts moving down in the die. The load cell measures the back pressure arising from the friction along the die walls $(P x)$ that corresponds to the minimum pressure to start the movement. All pellets were built up in sequential layers to mimic the process in large scale pellet mills. For each layer a maximum pressure of $200 \mathrm{MPa}$ with a holding time of $10 \mathrm{~s}$ was applied.

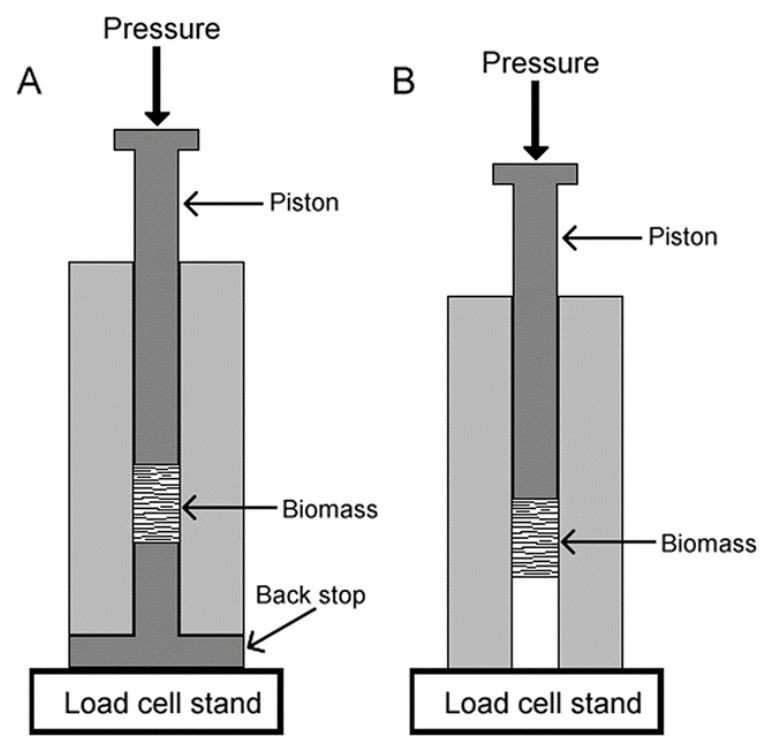

Figure 3. Working principle of the single pellet press. (A) Pellet production. (B) Back pressure measurement with the back stop removed ${ }^{38}$.

\section{RESULTS AND DISCUSSION}

An example of how the fitting of the model to the experimental data was carried out for WT giant reed at $60^{\circ} \mathrm{C}$ is shown in Figure 4 . The circular points in the figure correspond to the linear region, at small compression ratios, of pelletization pressure $\left(P_{x}\right)$ versus compression ratio. These values were used to determine the $U$ parameter of the model by adjusting a linear regression fit (red solid line). Then, the $J$ parameter was calculated by adjusting a nonlinear fit of Eq. 5 to all the measured data points from the single pellet press. So, a value of $U$ and $J$ parameters was obtained for each 
temperature. For all temperatures and low compression ratios, the $P_{x}$ values showed good linearity so it was acceptable to use a linear least-square fit to determine the $U$ parameter. It was not possible to achieve lower compression ratios because of the lowest detection limit of the load cell. However, the fittings for the different temperatures provided good results.

Figure 5 shows the $U$ and $J$ values found at different temperatures for WT giant reed. As previously observed by Holm et al. ${ }^{37}$ for untreated spruce and beech, the $U$ parameter shows a temperature dependence and it decreases, linearly, when the pelletizing temperature increases. However, it seems that there's no systematic correlation between $J$ parameter and the temperature. Following the procedure of Holm et al. ${ }^{37}$, the correlation between the $J$ parameter variation and the $U$ parameter variation was studied. This was done by assuming the linear fit given in Figure 5 for $U$ and using it to calculate a new $U$ value for each temperature. Then, the $J$ parameter was also recalculated for each temperature. The new $J$ values obtained still vary with the temperature, but the variations are smaller (10\% vs 15\% obtained before). The results for the recalculated model with the new $U$ and $J$ values are presented in Figure 6. This figure shows the experimentally obtained data points together with the curves obtained from the model considering linear $U$ values, according to Figure 5, and a constant $J$ value of 0.1097 (average value). The model can describe the experimentally obtained data of WT giant reed well and only at $80^{\circ} \mathrm{C}$ it really deviates from the last data point. This is due to an important increase of the pelletizing pressure at that point that it was not observed for the other temperatures. Even if each test was repeated a minimum of four times and the average value of all the repetitions was used, the difficulty of pressing out the pellets with the manual hydraulic press at that point may have affected the value measured by the load cell giving rise to higher logged values than the real ones. 


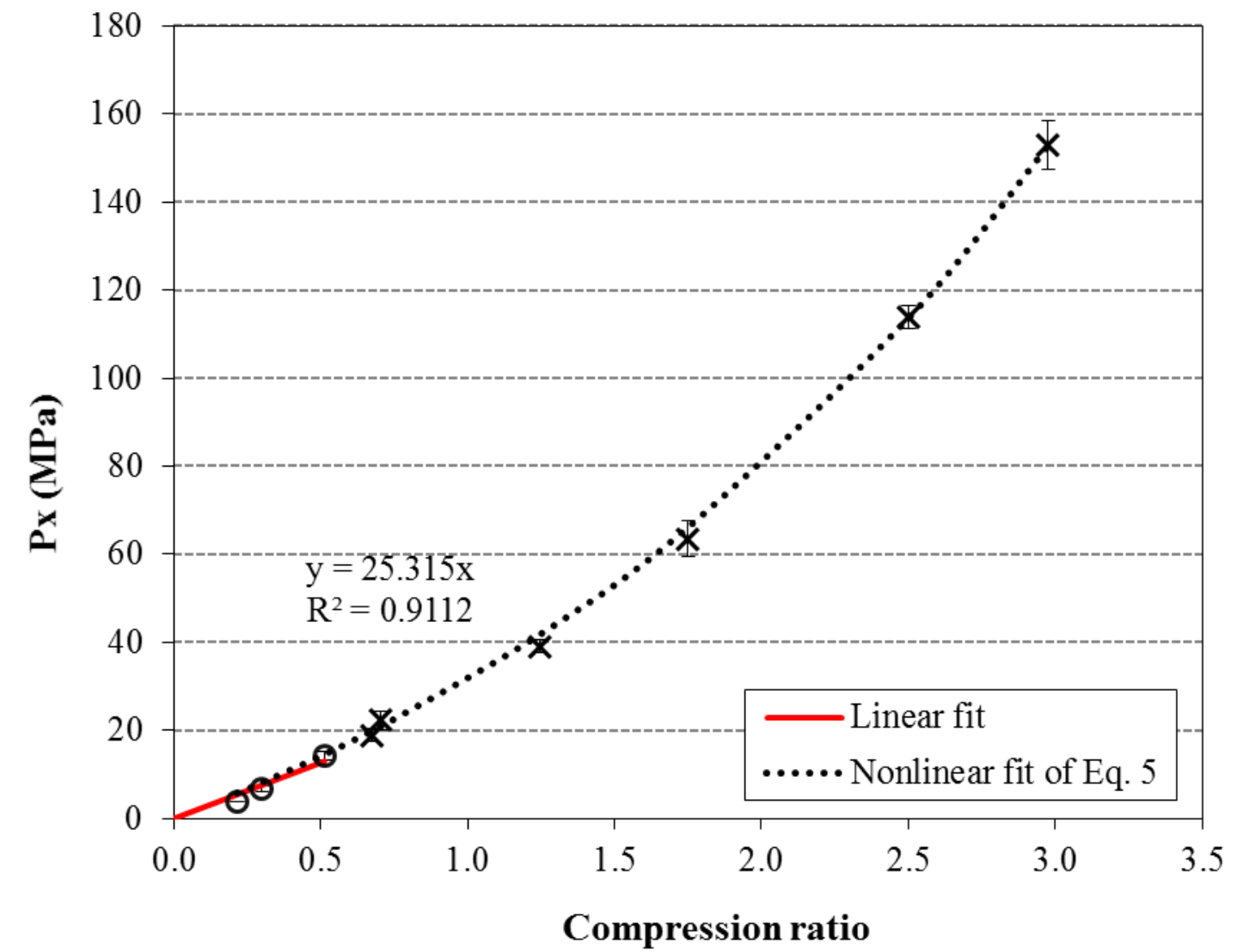

Figure 4. Experimental data and data fittings to determine the $U$ and $J$ parameters of the model for wet torrefied giant reed at $80^{\circ} \mathrm{C}$. Error bars indicate standard deviations of the measurements.

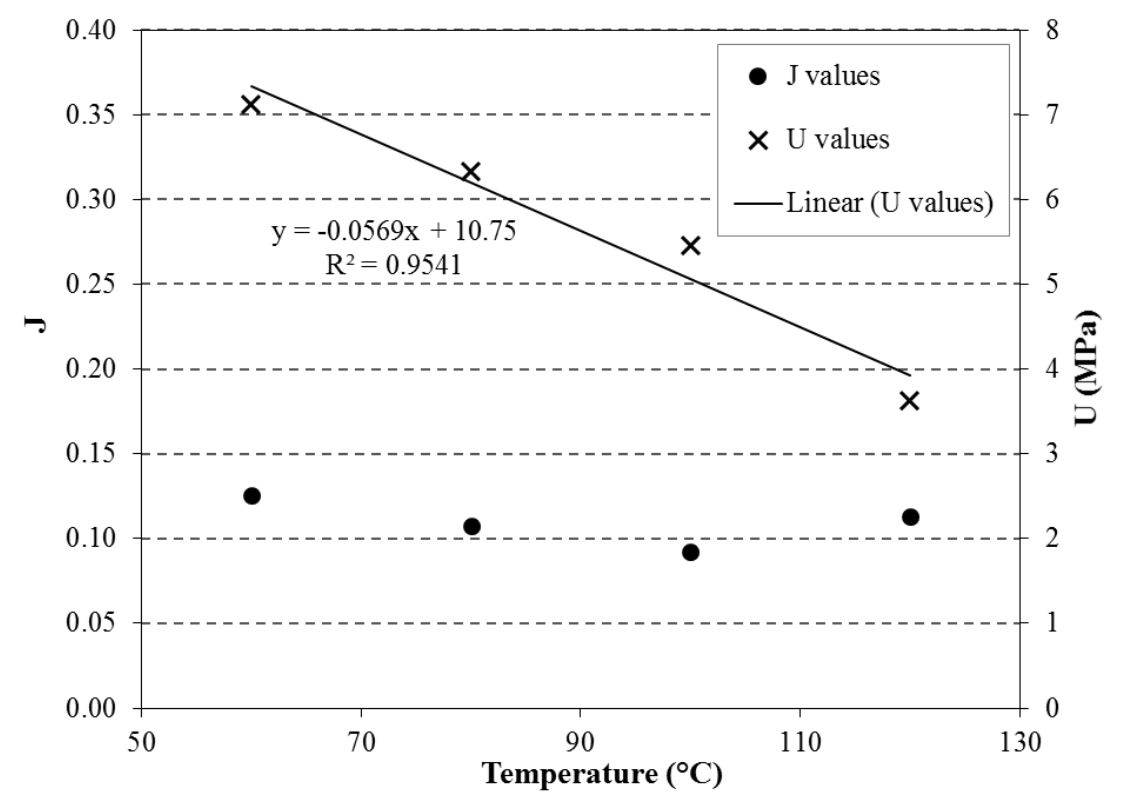


Figure 5. $U$ and $J$ values for wet torrefied giant reed at different pelletization temperatures.

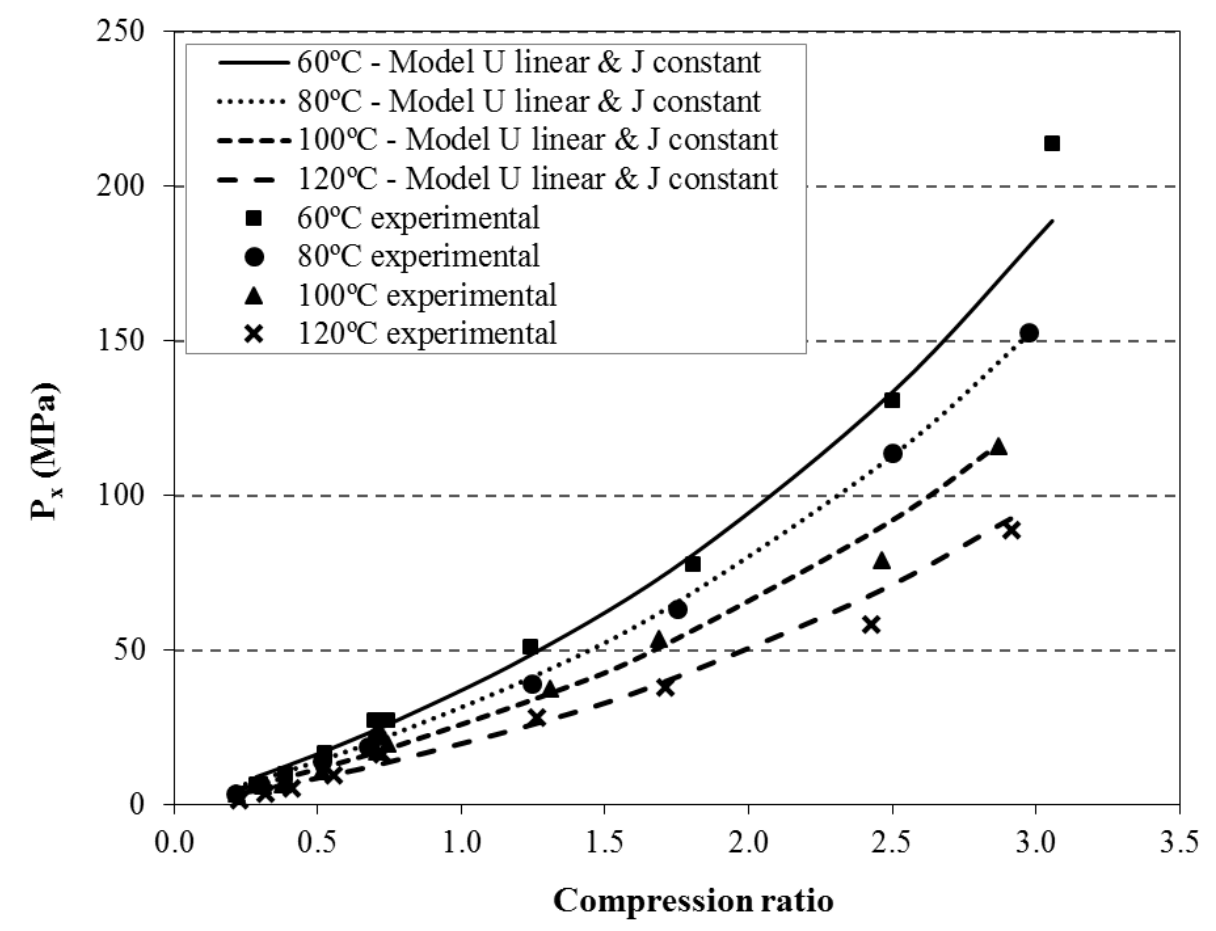

Figure 6. Pelletizing pressure of wet torrefied giant reed versus compression ratio for different die temperatures.

The same procedure as described before was followed for DT willow. $J$ and $U$ values found for different temperatures are presented in Figure 7. $U$ and $J$ parameters followed the same behavior than that observed for WT giant reed. In consequence, the linear fit given in Figure 7 for $U$ was assumed and new $J$ values were calculated for each temperature. Figure 8 shows the experimentally obtained data points together with the curves calculated using the model. Linear $U$ values, according to Figure 7, and a constant $J$ value of 0.0893 (average value) were considered. It can be observed how the model is also able to describe the experimental data of DT willow well. 


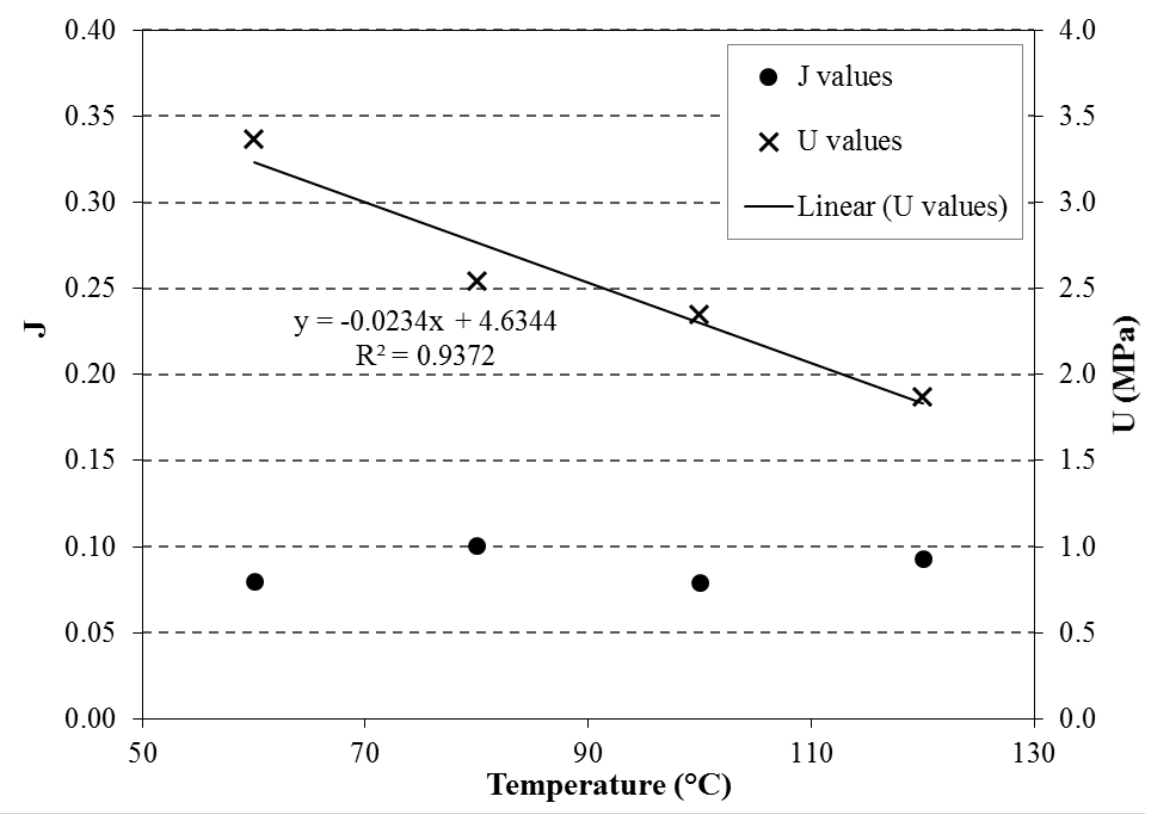

Figure 7. $U$ and $J$ values for torrefied willow at different pelletization temperatures.

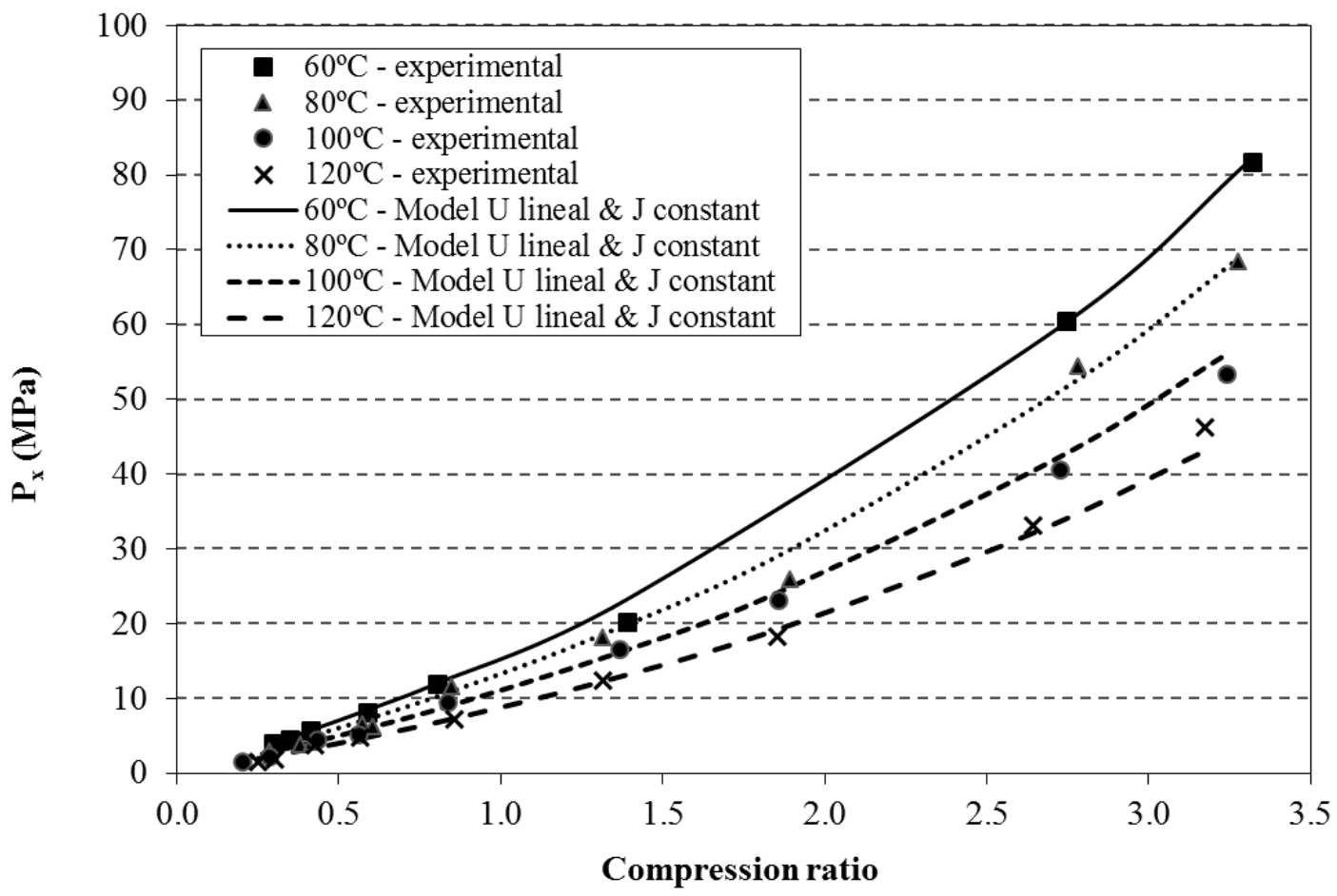

Figure 8. Pelletizing pressure of torrefied willow versus compression ratio for different die temperatures. 
Both Figure 6 and Figure 8 show that the temperature influence on the pelletization pressure for torrefied material can be explained by using the model described in Holm et al. ${ }^{37}$. The $U$ value is considered as a linear function of the temperature and $J$ is approximated by a constant. In both cases, as expected, increasing the pellet length increased the pressure needed to push the pellet out. It is known that the length of the press channel and the compression ratio are the most relevant factors affecting the pressure built up in the die of a pellet press ${ }^{36,42,20}$. Published data clearly indicates that there is an exponential correlation between the compression ratio and the built up pelletizing pressure ${ }^{43}$. On the other side, it was also observed how decreasing the die temperature also increased the pelletizing pressure. Stelte et al. ${ }^{44}$ suggested that the friction in the press channel is lowered due to polymer softening and extractive migration to the pellet surface caused by high temperatures. In addition, the glass transition temperature of lignin is likely increased during the torrefaction process due to the decrease of moisture in the biomass ${ }^{39}$. Thus, increasing the pelletizing temperature compensates for the increase of the softening temperature of the lignin and favors the extractive migration. Different studies have also indicated that temperature increase results in better pellet quality and less friction during pelletization ${ }^{27,33}$. Direct comparison between pelletization of wet and dry torrefied material cannot be made because different biomass species were used for each pretreatment. But comparing Figure 6 and Figure 8 shows how, at any temperature, DT willow requires less pelletization pressure than WT giant reed. It also shows how increasing the compression ratio causes a higher increase on the pelletization pressure of WT giant reed than of DT willow. When comparing the specific slopes of the linear fits for $U$ values (Figure 5 and Figure 7), WT giant reed shows a stronger temperature dependence. This means a faster decrease in friction when increasing the temperature for WT giant reed than for DT willow. DT willow presents a lower temperature dependence of the $U$ parameter when compared with WT giant reed. This could be related to a greater extractives content on DT willow. This point 
would also explain the lower pelletization pressure requirements of DT willow compared with WT giant reed observed in Figure 6 and Figure 8.

It is known that the pelletization pressure depends on the wood species, particle size distribution, extractives and moisture content. In consequence, some additional pelletizing experiments were carried out at different moisture contents and at a die temperature of $100^{\circ} \mathrm{C}$. These pellets were made with 4 sequential layers of $0.25 \mathrm{~g}$ each. The results are presented in Table 1 and show that, for the same moisture content, the pelletizing pressure of WT giant reed is always higher. However, WT giant reed shows a higher decrease of pelletizing pressure when increasing the moisture content while DT willow shows similar values for different moisture contents. The decrease of the pelletizing pressure can be explained by an increase in the molecular mobility of lignin and hemicelluloses and other low glass transition temperature extractives when increasing the moisture content. So, the different behavior between the two samples could be due to a different content of amorphous polymers and extractives. Another factor that could influence the higher pelletizing pressure required by WT giant reed is that it presents a particle size distribution dominated by smaller particles compared to DT willow (Figure 2).

Using two different kinds of biomass with two different pretreatments, doesn't allow the authors to conclude if possible different extractives and lignin contents are because of different biomass species or different thermal pretreatments. So, further investigations are required to evaluate the influence of different pretreatments and PSD on pelletization process.

Table 1. Single pellet press results for tests at die temperature of $100^{\circ} \mathrm{C}$ and $200 \mathrm{MPa}$. The value of the standard deviation of measured samples is given in brackets.

\begin{tabular}{llll}
\hline Species & $\begin{array}{l}\text { Moisture } \\
\text { content (wt\%) }\end{array}$ & Px (MPa) & Density $\left(\mathbf{k g} / \mathbf{m}^{3}\right)$ \\
\hline & $3 \%$ & $93.44(2.39)$ & $1341(3)$
\end{tabular}




\begin{tabular}{llll} 
& $5 \%$ & $83.00(5.37)$ & $1355(17)$ \\
$\begin{array}{l}\text { WT giant } \\
\text { reed }\end{array}$ & $10 \%$ & $51.19(2.63)$ & $1353(24)$ \\
& $15 \%$ & $32.85(5.41)$ & $1355(9)$ \\
\hline & $3 \%$ & $17.69(0.74)$ & $1189(15)$ \\
DT willow & $5 \%$ & $21.76(1.11)$ & $1203(17)$ \\
& $10 \%$ & $17.15(1.19)$ & $1189(16)$ \\
& $15 \%$ & $17.09(0.56)$ & $1090(37)$ \\
\hline
\end{tabular}

\section{CONCLUSIONS}

In the present work, it has been shown the usefulness of the pelletization model developed by Holm et al. ${ }^{36,37}$ to fit pelletization pressure data experimentally obtained in a single pellet press for torrefied material. Giant reed and willow have been used, the first one after undergoing a wet torrefaction (WT) pretreatment and the second one after a dry torrefaction (DT) pretreatment. The two model parameters ( $J$ and $U$ ) which result from the combination of $\mu, v_{L R}$ and $P_{N o}$ were determined. $U$ was determined by adjusting a linear fit to the pelletization pressure versus the compression ratio (c) for small values of $c$. $J$ was determined by fitting an equation of the model to all experimental data points, including higher $c$ values. For both materials, $U$ parameter decreases linearly when the temperature increases. This decrease is more pronounced for WT giant reed than for DT willow. A higher extractives content may lower this temperature dependence, resulting in a smaller slope of the $U$ curve. On the other side, the $J$ parameter remains more or less constant without a clear temperature dependence. The model shows good agreement with the experimental data when $J$ is regarded as a fixed constant value and $U$ parameter follows the linear temperature 
dependence. Therefore, the model has been a useful and reliable tool to evaluate the pelletizing behavior of thermally pretreated materials.

\title{
Acknowledgements
}

The authors thank the financial support received from the European Community’s Seventh Framework Programme (FP7/2007-2013) as part of the project "LogistEC - Logistics for Energy Crops’ Biomass” (FP7 - 311858). The views expressed in this work are the sole responsibility of the authors and do not necessary reflect the views of the European Comission.

\author{
Abbreviations \\ DT: Dry Torrefaction \\ HTC: Hydrothermal carbonization \\ WT: Wet Torrefaction \\ $c$ : compression ratio \\ $\mu$ : sliding friction coefficient \\ $v$ : Poisson's ratio \\ $J$ : model parameter $\left(J=\mu v_{L R}\right)$ \\ $P_{N O}:$ prestressing pressure \\ $P_{x}$ : pressure needed to press out a pellet of length $x$ \\ $r$ : radius of the die channel \\ $U$ : model parameter $\left(U=\mu P_{N 0}\right)$ \\ $x$ : length of the die channel
}




\section{References}

(1) Tumuluru, J. S.; Hess, J. R.; Boardman, R. D.; Wright, C. T.; Westover, T. L. Ind. Biotechnol. 2012, 8 (3), 113-132.

(2) Bach, Q.-V.; Skreiberg, Ø. Renew. Sustain. Energy Rev. 2016, 54, 665-677.

(3) Acharya, B.; Dutta, A.; Minaret, J. Sustain. Energy Technol. Assessments 2015, 12, 26 -37.

(4) Castellano, J. M.; Gómez, M.; Fernández, M.; Esteban, L. S.; Carrasco, J. E. Fuel 2015, 139, 629-636.

(5) Nhuchhen, D. R.; Basu, P.; Acharya, B. Int. J. Renew. Energy Biofuels 2014, 2014.

(6) van der Stelt, M. J. C.; Gerhauser, H.; Kiel, J. H. A.; Ptasinski, K. J. Biomass and Bioenergy 2011, 35 (9), 3748-3762.

(7) Chen, W.-H.; Peng, J.; Bi, X. T. Renew. Sustain. Energy Rev. 2015, 44, 847-866.

(8) Bach, Q.-V.; Tran, K.-Q.; Khalil, R. A.; Skreiberg, Ø.; Seisenbaeva, G. Energy \& Fuels 2013, 27 (11), 6743-6753.

(9) Bach, Q.-V.; Tran, K.-Q.; Skreiberg, Ø.; Khalil, R. A.; Phan, A. N. Fuel 2014, 137, 375-383.

(10) Bach, Q.-V.; Tran, K.-Q.; Skreiberg, Ø.; Trinh, T. T. Energy 2015, 88, 443-456.

(11) ECN. Available online: www.ecn.nl. Available online: www.ecn.nl 2014.

(12) Shang, L.; Nielsen, N. P. K.; Dahl, J.; Stelte, W.; Ahrenfeldt, J.; Holm, J. K.; Thomsen, T.; Henriksen, U. B. Fuel Process. Technol. 2012, 101, 23-28.

(13) Shang, L.; Stelte, W.; Ahrenfeldt, J.; Holm, J. K.; Bach, L. S.; Thomsen, T.; Zhang, R. Z.; Luo, Y. H.; Henriksen, U. B. In World Sustainable Energy Days - WSEDnext conference, Wels, Austria, 29 February - 2 March; 2012.

(14) Bridgeman, T. G.; Jones, J. M.; Shield, I.; Williams, P. T. Fuel 2008, 87 (6), 844-856.

(15) Arias, B.; Pevida, C.; Fermoso, J.; Plaza, M. G.; Rubiera, F.; Pis, J. J. Fuel Process. Technol. 
2008, 89 (2), 169-175.

(16) Svoboda, K.; Pohořelý, M.; Hartman, M.; Martinec, J. Fuel Process. Technol. 2009, 90 (5), 629-635.

(17) Couhert, C.; Salvador, S.; Commandré, J.-M. Fuel 2009, 88 (11), 2286-2290.

(18) Hilten, R. N.; Speir, R. A.; Kastner, J. R.; Mani, S.; Das, K. C. Energy \& Fuels 2013, 27 (2), 830-843.

(19) Meng, J.; Park, J.; Tilotta, D.; Park, S. Bioresour. Technol. 2012, 111, 439-446.

(20) Stelte, W. Guideline: Densification of torrefied biomass; 2012.

(21) Peng, J. H.; Bi, X. T.; Sokhansanj, S.; Lim, C. J. Fuel 2013, 111, 411-421.

(22) Peng, J. H.; Bi, H. T.; Lim, C. J.; Sokhansanj, S. Energy \& Fuels 2013, 27 (2), 967-974.

(23) Mišljenović, N.; Bach, Q.-V. V.; Tran, K.-Q. Q.; Salas-Bringas, C.; Skreiberg, Ø. Energy \& Fuels 2014, 28 (4), 2554-2561.

(24) Stelte, W.; Clemons, C.; Holm, J. K.; Sanadi, A. R.; Ahrenfeldt, J.; Shang, L.; Henriksen, U. B. Biomass and Bioenergy 2011, 35 (11), 4690-4698.

(25) Shang, L.; Nielsen, N. P. K.; Stelte, W.; Dahl, J.; Ahrenfeldt, J.; Holm, J. K.; Puig-Arnavat, M.; Bach, L. S.; Henriksen, U. B. BioEnergy Res. 2013, 7 (1), 87-94.

(26) Li, H.; Liu, X.; Legros, R.; Bi, X. T.; Jim Lim, C.; Sokhansanj, S. Appl. Energy 2012, 93, 680-685.

(27) Larsson, S. H.; Rudolfsson, M.; Nordwaeger, M.; Olofsson, I.; Samuelsson, R. Appl. Energy 2013, 102, 827-832.

(28) Bach, Q.-V.; Misljenovic, N.; Tran, K.-Q.; Salas-Bringas, C.; Skreiberg, Ø. Annu. Trans. Nord. Rheol. Soc. 2014, 22, 61-68.

(29) Hoekman, S. K.; Broch, A.; Warren, A.; Felix, L.; Irvin, J. Biofuels 2014, 5 (6), 651-666.

(30) Reza, M. T.; Lynam, J. G.; Vasquez, V. R.; Coronella, C. J. Environ. Prog. Sustain. Energy 
2012, 31 (2), 225-234.

(31) Reza, M. T.; Uddin, M. H.; Lynam, J. G.; Coronella, C. J. Biomass and Bioenergy 2014, 63, 229-238.

(32) Kambo, H. S.; Dutta, A. Appl. Energy 2014, 135, 182-191.

(33) Rudolfsson, M.; Stelte, W.; Lestander, T. A. Appl. Energy 2015, 140, 378-384.

(34) Nielsen, N. P. K.; Holm, J. K.; Felby, C. Energy \& Fuels 2009, 23 (6), 3211-3216.

(35) Tumuluru, J. S.; Wright, C. T.; Kenney, K. L.; Hess, J. R. ASABE Meet. Present. Pap. Number 10094012010.

(36) Holm, J. K.; Henriksen, U. B.; Hustad, J. E.; Sørensen, L. H. Energy \& Fuels 2006, 20 (6), 2686-2694.

(37) Holm, J. K.; Stelte, W.; Posselt, D.; Ahrenfeldt, J.; Henriksen, U. B. Energy \& Fuels 2011, 25 (8), 3706-3711.

(38) Holm, J. K.; Henriksen, U. B.; Wand, K.; Hustad, J. E.; Posselt, D. Energy \& Fuels 2007, 21 (4), 2446-2449.

(39) Stelte, W. Danish Technol. Inst. Cent. Biomass Biorefinery 2014.

(40) ECN. Deliverable D3.4: Assessment of improved pre-treatment technologies; 2012.

(41) Puig-Arnavat, M.; Shang, L.; Sárossy, Z.; Ahrenfeldt, J.; Henriksen, U. B. Fuel Process. Technol. 2016, 142, 27-33.

(42) Stelte, W.; Sanadi, A. R.; Shang, L.; Holm, J. K.; Ahrenfeldt, J.; Henriksen, U. B. Bioresources 2012, August.

(43) Faborode, M. O.; O’Callaghan, J. R. J. Agric. Eng. Res. 1987, 38 (4), 245-262.

(44) Stelte, W.; Holm, J. K.; Sanadi, A. R.; Barsberg, S.; Ahrenfeldt, J.; Henriksen, U. B. Fuel 2011, 90 (11), 3285-3290. 